\title{
Validation of the graded prognostic assessment for gastrointestinal cancers with brain metastases (GI-GPA)
}

\author{
Carsten Nieder ${ }^{1,2^{*}} \mathbb{D}$, Mandy Hintz ${ }^{3}$, llinca Popp ${ }^{3,4}$, Angelika Bilger ${ }^{3,4}$ and Anca L. Grosu 3,4
}

\begin{abstract}
Purpose: The purpose of this study was to validate a new prognostic model (GI-GPA) originally derived from a multi-center database (USA, Canada, Japan).

Patients and Methods: This retrospective study included 92 German and Norwegian patients treated with individualized approaches, always including brain radiotherapy. Information about age, extracranial spread, number of brain metastases, performance status and other variables was collected. The GI-GPA score was calculated as described by Sperduto et al.

Results: Median survival was 4 months. The corresponding figures for the 4 different prognostic strata were 2.3, 4.4, 9.4 and 12.7 months, respectively $(p=0.0001)$. Patients whose management included surgical resection had longer median survival than those who were treated with other approaches (median 11.9 versus 3.0 months, $p=0.002$ ). Comparable results were seen for additional systemic therapy (median 8.5 versus 3.5 months, $p=0.01$ ).

Conclusion: These results confirm the validity of the GI-GPA in an independent dataset from a different geographical region, despite the fact that overall survival was shorter in all prognostic strata, compared to Sperduto et al. Potential explanations include differences in molecular tumor characteristics and treatment selection, both brain metastasesdirected and extracranially. Long-term survival beyond 5 years is possible in a small minority of patients.
\end{abstract}

Keywords: Brain metastases, Gastrointestinal cancer, Radiotherapy, Prognostic factors

\section{Introduction}

According to recent data, survival of patients with brain metastases from gastrointestinal cancers has improved [1]. However, prognosis and eligibility for different treatment options varies with performance status, number of brain metastases and patterns of extracranial disease extent [2-7]. Given that brain metastases can occur early or late during the disease trajectory, management decisions are not always simple and straightforward [8,9]. Despite progress, a median overall survival of 8 months [1] can still be considered disappointing.

Prognostic scores have long been used to support decision making and to stratify patients for research purposes
$[10,11]$. Models such as the graded prognostic assessment (GPA) $[12,13]$ have been validated in several studies and adopted by many clinicians. Recently, these tools have been updated to further refine their performance [14-16]. This is also true for the GPA for gastrointestinal primary tumors (GI-GPA) [1]. The latter 4-tiered score is based on Karnofsky performance status (KPS), age (cut-off 60 years), number of brain metastases and presence of extracranial metastases, while its predecessor solely reflected variations in KPS. The purpose of the present study was to validate the GI-GPA in an independent cohort of patients from Germany and Norway, hypothesizing that a validated score would gain wide acceptance.

\section{Material and methods \\ Patients and treatment}

A retrospective study based on chart review of 92 patients with irradiated brain metastases from GI cancers

\footnotetext{
* Correspondence: carsten.nieder@nlsh.no

'Department of Oncology and Palliative Medicine, Nordland Hospital, 8092 Bodø, Norway

2Department of Clinical Medicine, Faculty of Health Sciences, University of Tromsø, 9037 Tromsø, Norway

Full list of author information is available at the end of the article
}

(C) The Author(s). 2020 Open Access This article is distributed under the terms of the Creative Commons Attribution 4.0 International License (http://creativecommons.org/licenses/by/4.0/), which permits unrestricted use, distribution, and reproduction in any medium, provided you give appropriate credit to the original author(s) and the source, provide a link to the Creative Commons license, and indicate if changes were made. The Creative Commons Public Domain Dedication waiver (http://creativecommons.org/publicdomain/zero/1.0/) applies to the data made available in this article, unless otherwise stated. 
was performed. Patients managed with best supportive care rather than primary or post-operative radiotherapy were excluded. Treatment was individualized and consisted of focal therapies such as surgery, radiosurgery and stereotactic fractionated radiotherapy with or without whole-brain radiotherapy (WBRT), or upfront WBRT alone with total doses in the range of 20-40 Gy (5-20 fractions). According to the intention-to-treat principle, patients who failed to complete all fractions of radiotherapy were included in the study. Sequential salvage treatment of new or progressive intracranial lesions was individualized. All approaches mentioned above were considered at the time of relapse or progression. Systemic treatment before and after brain-directed measures was usually prescribed as judged appropriate by the patients' medical oncologists. The patients (allcomers) were treated consecutively between 2005 and 2018 and identified from a previously described database [15-17], which includes data from the radiotherapy centers in Bodø and Freiburg. Prognosis was estimated on the basis of age, KPS, extracranial metastases and number of brain metastases as described in the recent GIGPA publication [1] and shown in Table 1. Differences to the previous GPA score are also shown in the table.

\section{Statistical methods}

Actuarial survival from the first day of radiotherapy or from surgery was calculated employing the KaplanMeier method, and different groups were compared using the log-rank test (SPSS 25, IBM Corp., Armonk, NY, USA). Date of death was known in all but 3 patients. The latter were included as censored observations after a median follow-up of 70 months. Uni- and multivariate Cox regression analysis was also performed (forward conditional method).

Table 1 Baseline characteristics included in the GI-GPA (Sperduto et al. 2019 [1]): minimum point sum 0 (poor prognosis), maximum point sum 4 (good prognosis)

\begin{tabular}{lll}
\hline Parameter & GI-GPA & DS-GPA \\
\hline Metastatic spread to extracranial sides & 0 & \\
Brain metastases only & 0.5 & \\
Age $\geq 60$ years & 0 & \\
Age $<60$ years & 0.5 & 1 if 70 \\
Karnofsky performance status $\leq 70$ & 0 & 2 \\
Karnofsky performance status 80 & 1 & 3 if 90,4 if 100 \\
Karnofsky performance status $90-100$ & 2 & \\
Number of brain metastases $>3$ & 0 & \\
Number of brain metastases 2-3 & 0.5 & \\
Number of brain metastases 1 & 1 & \\
\hline
\end{tabular}

KPS Karnofsky performance status

aincludes patients with delayed (salvage) neurosurgery, radiosurgery, fractionated re-irradiation

\section{Results}

\section{Patient characteristics}

The median age was 65 years (range 40-85). The median KPS was 70 (range 50-100). Most patients developed brain metastases late during the course of disease (median time interval after cancer diagnosis 26 months, range $0-143)$. The most common initial treatment approach was primary WBRT alone (53\%), followed by surgery with or without post-operative radiotherapy (35\%). The use of sequential systemic therapy was not well documented, except for 35 patients (19 received additional anti-cancer drugs while 16 did not). Further patient characteristics are shown in Table 2.

\section{GI-GPA}

Most patients had unfavorable prognostic features, i.e. $0-1$ point in 45 patients $(49 \%)$ and $1.5-2$ points in 24 (26\%). Fourteen patients (15\%) had $2.5-3$ points and the remaining 9 (10\%) had 3.5-4 points. These four prognostic strata had significantly different median survival of 2.3, 4.4, 9.4 and 12.7 months $(p<0.0001, \log$-rank test pooled over all strata, Fig. 1). Overall median survival was 4.0 months. Table 3 shows the results of univariate prognostic factors for survival. In multivariate Cox regression analysis KPS (3 strata, $p=0.0001$ ), number of

Table 2 Patient characteristics

\begin{tabular}{|c|c|c|}
\hline Parameter & Number & Percent \\
\hline Male gender & 56 & 61 \\
\hline Female gender & 36 & 39 \\
\hline Colon cancer & 37 & 40 \\
\hline Rectal cancer & 34 & 37 \\
\hline Esophageal cancer & 14 & 15 \\
\hline Other Gl cancer (gastric, pancreatic etc.) & 7 & 8 \\
\hline Extracranial metastases & 68 & 74 \\
\hline No extracranial metastases & 24 & 26 \\
\hline Single brain metastasis & 37 & 40 \\
\hline $2-3$ brain metastases & 31 & 34 \\
\hline$>3$ brain metastases & 24 & 26 \\
\hline Age $<60$ years & 26 & 28 \\
\hline Age $\geq 60$ years & 66 & 72 \\
\hline KPS $<80$ & 55 & 60 \\
\hline KPS 80 & 16 & 17 \\
\hline KPS 90-100 & 21 & 23 \\
\hline Upfront whole brain radiotherapy ${ }^{a}$ & 49 & 53 \\
\hline Upfront neurosurgery & 32 & 35 \\
\hline Upfront radiosurgery & 7 & 8 \\
\hline Upfront stereotactic fractionated radiotherapy & 4 & 4 \\
\hline
\end{tabular}

KPS Karnofsky performance status

aincludes patients with delayed (salvage) neurosurgery, radiosurgery, fractionated re-irradiation 


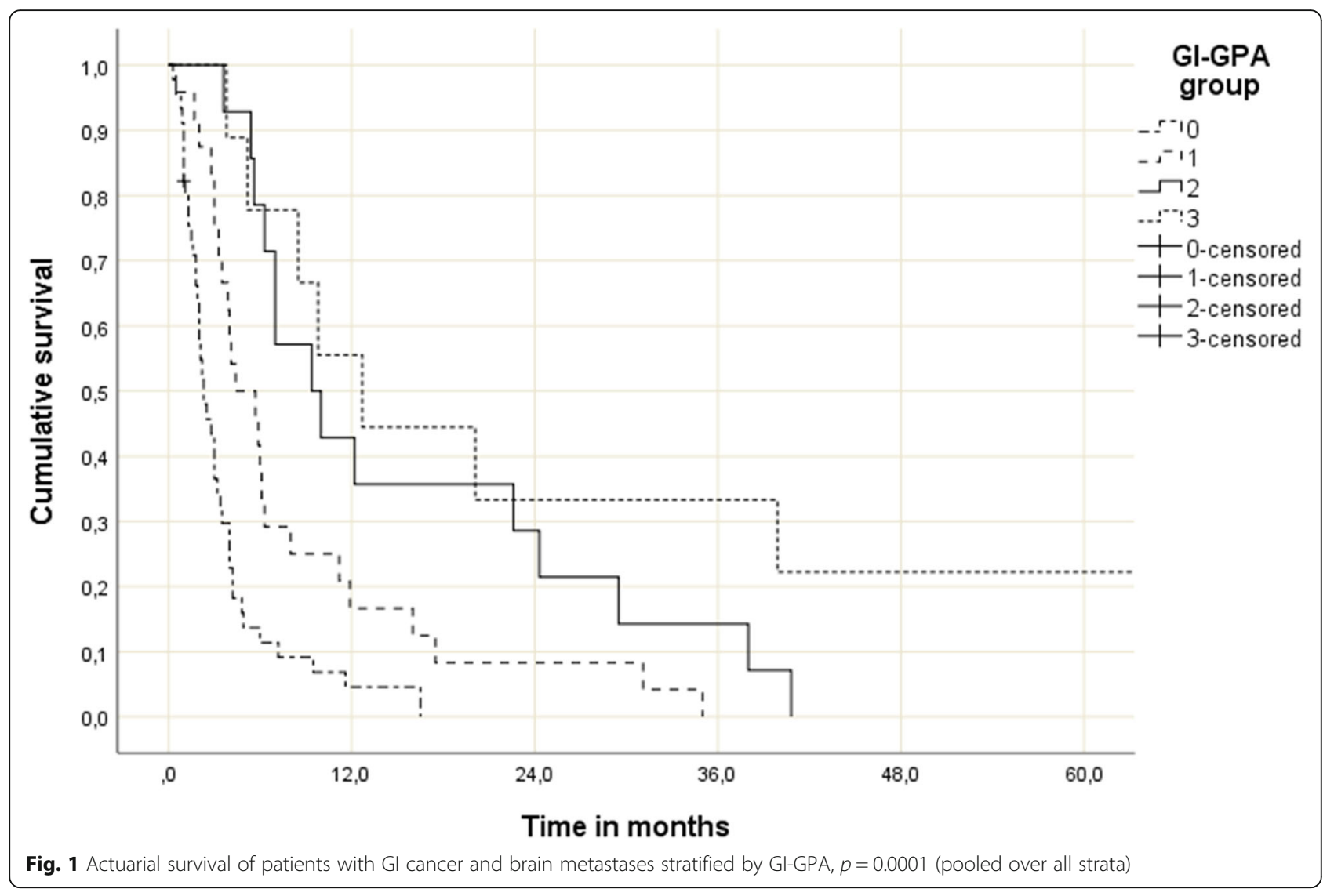

brain metastases ( 3 strata, $\mathrm{p}=0.0001$ ) and extracranial metastases ( 2 strata, $p=0.04$ ) were significant predictors of survival.

\section{Further survival results}

Patients whose management included surgical resection had longer median survival than those who were treated with other approaches (median 11.9 versus 3.0 months, $p=0.002$ ). Comparable results were seen for additional systemic therapy (median 8.5 versus 3.5 months, $p=0.01$ ).

Table 3 Significant prognostic factors for overall survival (logrank test or, for continuous variables, Cox regression)

\begin{tabular}{lll}
\hline Parameter & Median survival in months & $p$-value \\
\hline Extracranial metastases & 3.0 & \\
No extracranial metastases & 9.4 & 0.001 \\
Single brain metastasis & 8.5 & \\
2-3 brain metastases & 4.1 & 0.0001 \\
More than 3 brain metastases & 2.5 & \\
Age $<60$ years & 4.9 & 0.6 \\
Age $\geq 60$ years & 4.0 & 0.9 \\
Age as continuous variable & & 0.0001 \\
KPS as continuous variable & &
\end{tabular}

KPS Karnofsky performance status
Time interval to development of brain metastases was not prognostic. Regarding primary tumor site, the following median results were observed: esophageal cancer 5.4 months, rectal cancer 5.2 months, colon cancer 3.8 months, others 2.3 months ( $p=0.18$, log-rank test pooled over all strata). All patients who survived for 3 or more years had colorectal primary tumors. In the poorprognosis group (0-1 points) median survival was 2.0 months after WBRT and 4.2 months after other approaches. The corresponding 1-year survival rate was 0 and $15 \%$, respectively.

\section{Discussion}

We report an independent validation study of the GIGPA [1] in a European patient population, comparable to the previous validation of the Lung-molGPA [16] and the Melanoma-molGPA [15]. The study cohort consisted mainly of patients with poor or intermediate prognosis who were judged not to be appropriate candidates for aggressive local therapies, such as surgery or stereotactic radiotherapy. Nevertheless, all patients received active brain-metastases-directed therapy. Different treatment intensity and heterogeneity of gastrointestinal tumors (site, histology, molecular features) in part explains why the median survival in our study was 4 months, while the patients analyzed by Sperduto et al. [1] survived for 
a median of 8 months. Other treatments (chemotherapy, targeted drugs, salvage of brain metastases) might have differed too, however, they were not recorded in many of the patients. In the present study, additional systemic therapy was associated with significantly better survival (median 8.5 versus 3.5 months), consistent with a previous report [18]. Given that extracranial metastases were present in most patients (74\%; Sperduto et al.: 79\%), it is understandable that lack of extracranial disease control will negatively affect survival in this population. Although under continued investigation, systemic braindirected therapy is uncommonly prescribed [19].

Median time interval from initial cancer diagnosis to brain metastases was 26 months (Sperduto et al.: 23 months), which represents a longer interval than in other primary tumors, e.g. lung cancer $[8,12]$. Our study population was heavily weighted towards colorectal primary tumors $(77 \%$; Sperduto et al.: 54\%). Sperduto et al. reported that primary tumor site significantly influenced survival, although this variable was not included in the GI-GPA score. The same was true for serum hemoglobin. Other reports have also suggested that patients with gastric or pancreatic cancer constitute a minority of GI cancer patients who develop brain metastases [20, 21]. Thirty-one percent of the patients analyzed by Sperduto et al. [1] had KPS 90-100, compared to only $23 \%$ of our patients. Interestingly, survival was shorter in our study even for each different GI-GPA group (Table 4). Besides explanations discussed earlier, this could also result from differences in the diagnostic setting (imaging in asymptomatic patients vs. clinical deficits), causing a potential lead time bias if the patients in the Sperduto et al. cohort were treated earlier. In principle, the difference in patient numbers (92 compared to 792) may have contributed to different results, too. It would be interesting to see additional studies in patients managed with different approaches in different regions of the world.

The main result of our study was that the GI-GPA accurately reflects the prognostic impact of different baseline characteristics, although we did not see a significant impact of age (possibly due to the difference in statistical power). In the study reported by Sperduto et al. discrimination between the two favorable groups was better than in ours, either, and most likely, due to the larger numbers of patients or the variable impact of age in the two studies. When looking at both studies together, the GI-GPA score seems to represent a useful improvement of its ancestors such as DS-GPA [12, 22]. Age, KPS and number of brain metastases were also part of a previously published nomogram (227 patients from Italy, all with colorectal cancer) [11].

Limitations of this study, which followed the methods used in previous validation studies $[15,16]$, include the small number of patients, which were recruited over a long period of more than 10 years, statistical power of subgroup analyses, and retrospective design. Given that patients managed with best supportive care were excluded, worse survival outcomes could be expected if one would analyze all patients with a brain metastasis diagnosis. In selected patients survival beyond 5 year was observed, in line with Sperduto et al. [1] and other authors [23-26]. These results lend support to the current clinical practice of surgical resection and/or ablative radiotherapy for oligometastatic lesions. The results also confirm the limited median survival after primary WBRT reported previously [27]. Sperduto et al. [1] found median survival of 3 months, which is identical to the present analysis. They suggested that best supportive care may be considered if the GI-GPA indicates a poor prognosis ( $0-1$ points). In our poor-prognosis group median survival was 2.0 months after WBRT and 4.2 months after other approaches. The corresponding 1 -year survival rate was 0 and $15 \%$, respectively. Thus, individual assessment and multi-disciplinary decision making is recommended to identify those patients who might benefit from active therapy.

\section{Conclusions}

The data presented in this study confirm the validity of the GI-GPA in patients from a different geographical region. However, median survival was shorter in all prognostic strata. Potential explanations include differences in treatment selection, both brain metastases-directed and with systemic agents. Long-term survival beyond 5 years is possible in a small minority of patients.

Table 4 Survival outcomes stratified by study

\begin{tabular}{llll}
\hline Group & Median survival in months & 6 -month probability & 12-month probability $^{\text {a }}$ \\
\hline $0-1$ p. & 2.3 & $11 \%$ & $5 \%$ \\
Sperduto et al. 0-1 p. & 3 & $30 \%$ & $14 \%$ \\
$1.5-2$ p. & 4.4 & $38 \%$ & $13 \%$ \\
Sperduto et al. 1.5-2 p. & 7 & $53 \%$ & $37 \%$ \\
2.5-3 p. & 9.4 & $71 \%$ & $36 \%$ \\
Sperduto et al. 2.5-3 p. & 11 & $67 \%$ & $47 \%$ \\
3.5-4 p. & 12.7 & $78 \%$ & $56 \%$ \\
Sperduto et al. 3.5-4 p. & 17 & $87 \%$ & $68 \%$ \\
\hline
\end{tabular}

aestimated from [1] Fig. 1 


\section{Abbreviations}

DS-GPA: Disease-specific graded prognostic assessment; Gl: Gastrointestinal; GI-GPA: Graded prognostic assessment for gastrointestinal primary tumors; GPA: Graded prognostic assessment; KPS: Karnofsky performance status; molGPA: Molecular markers in graded prognostic assessment; WBRT: wholebrain radiotherapy

\section{Acknowledgements}

Not applicable.

\section{Authors' contributions}

$\mathrm{CN}$ and $\mathrm{MH}$ analyzed and interpreted the patient data regarding the prognostic model. CN and ALG drafted the manuscript. IP and AB collected references and were major contributors in writing the manuscript. All authors read and approved the final manuscript.

\section{Funding}

The publication charges for this article have been funded by a grant from the publication fund of UiT The Arctic University of Norway.

\section{Availability of data and materials}

The dataset supporting the conclusions of this article is available at request from the corresponding author, if intended to be used for meta-analyses.

\section{Ethics approval and consent to participate}

As a retrospective quality of care analysis, no approval from the Regional Committee for Medical and Health Research Ethics (REK Nord) was necessary. This research project was carried out according to our institutions' guidelines and with permission to access the patients' data.

\section{Consent for publication}

Not applicable.

\section{Competing interests}

The authors declare that they have no competing interests.

\section{Author details}

'Department of Oncology and Palliative Medicine, Nordland Hospital, 8092 Bodø, Norway. ${ }^{2}$ Department of Clinical Medicine, Faculty of Health Sciences, University of Troms $\varnothing, 9037$ Tromsø, Norway. ${ }^{3}$ Department of Radiation Oncology, University Hospital Freiburg, 79106 Freiburg, Germany. ${ }^{4}$ German Cancer Consortium (DKTK), Partner Site Freiburg, Freiburg, Germany.

Received: 25 November 2019 Accepted: 4 February 2020

Published online: 13 February 2020

\section{References}

1. Sperduto PW, Fang P, Li J, Breen W, Brown PD, Cagney D, Aizer A, Yu JB, Chiang V, Jain S, Gaspar LE, Myrehaug S, Sahgal A, Braunstein S, Sneed P, Cameron B, Attia A, Molitoris J, Wu CC, Wang TJC, Lockney NA, Beal K, Parkhurst J, Buatti JM, Shanley R, Lou E, Tandberg DD, Kirkpatrick JP, Shi D, Shih HA, Chuong M, Saito H, Aoyama H, Masucci L, Roberge D, Mehta MP. Estimating survival in patients with gastrointestinal cancers and brain metastases: an update of the graded prognostic assessment for gastrointestinal cancers (GI-GPA). Clin Transl Radiat Oncol. 2019;18:39-45.

2. Nieder C, Hintz M, Grosu AL. Colorectal cancer metastatic to the brain: analysis of prognostic factors and impact of KRAS mutations on presentation and outcome. Clin Transl Oncol. 2016;18:88-92.

3. Michl M, Thurmaier J, Schubert-Fritschle G, Wiedemann M, Laubender RP, Nüssler NC, Ruppert R, Kleeff J, Schepp W, Reuter C, Löhe F, Karthaus M, Neumann J, Kirchner T, Engel J, Heinemann V. Brain metastasis in colorectal cancer patients: survival and analysis of prognostic factors. Clin Colorectal Cancer. 2015;14:281-90.

4. Magni E, Santoro L, Ravenda PS, Leonardi MC, Bonomo G, Monfardini L, Nolè F, Zampino MG. Brain metastases from colorectal cancer: main clinical factors conditioning outcome. Int J Color Dis. 2014;29:201-8.

5. Suzuki Y, Yamaguchi T, Matsumoto H, Nakano D, Honda G, Shinoura N, Karasawa K, Takahashi K. Prognostic factors and treatment effects in patients with curatively resected brain metastasis from colorectal cancer. Dis Colon Rectum. 2014;57:56-63.
6. Fokas E, Henzel M, Hamm K, Surber G, Kleinert G, Engenhart-Cabillic R. Multidisciplinary treatment of brain metastases derived from colorectal cancer incorporating stereotactic radiosurgery: analysis of 78 patients. Clin Colorectal Cancer. 2011;10:121-5.

7. Kruser TJ, Chao ST, Elson P, Barnett GH, Vogelbaum MA, Angelov L, Weil RJ, Pelley R, Suh JH. Multidisciplinary management of colorectal brain metastases. Cancer. 2008;113:158-65.

8. Carapella CM, Gorgoglione N, Oppido PA. The role of surgical resection in patients with brain metastases. Curr Opin Oncol. 2018;30:390-5.

9. Sittenfeld SMC, Suh JH, Murphy ES, Yu JS, Chao ST. Contemporary management of 1-4 brain metastases. Front Oncol. 2018;8:385.

10. Nieder C, Mehta MP, Geinitz H, Grosu AL. Prognostic and predictive factors in patients with brain metastases from solid tumors: a review of published nomograms. Crit Rev Oncol Hematol. 2018;126:13-8.

11. Pietrantonio F, Aprile G, Rimassa L, Franco P, Lonardi S, Cremolini C, Biondani P, Sbicego EL, Pasqualetti F, Tomasello G, Niger M, Casagrande M, Ghidini M, Muni R, Montrone S, Bergamo F, Berenato R, Fontanella C, Bozzarelli S, Moretto R, Battaglin F, Di Bartolomeo M, de Braud F, Miceli R. A new nomogram for estimating survival in patients with brain metastases secondary to colorectal cancer. Radiother Oncol. 2015;117:315-21.

12. Sperduto PW, Chao ST, Sneed PK, Luo X, Suh J, Roberge D, Bhatt A, Jensen AW, Brown PD, Shih H, Kirkpatrick J, Schwer A, Gaspar LE, Fiveash JB, Chiang V, Knisely J, Sperduto CM, Mehta M. Diagnosis-specific prognostic factors, indexes, and treatment outcomes for patients with newly diagnosed brain metastases: a multi-institutional analysis of 4,259 patients. Int J Radiat Oncol Biol Phys. 2010;77:655-61.

13. Sperduto PW, Kased N, Roberge D, Xu Z, Shanley R, Luo X, Sneed PK, Chao ST, Weil RJ, Suh J, Bhatt A, Jensen AW, Brown PD, Shih HA, Kirkpatrick J, Gaspar LE, Fiveash JB, Chiang V, Knisely JP, Sperduto CM, Lin N, Mehta M. Summary report on the graded prognostic assessment: an accurate and facile diagnosis-specific tool to estimate survival for patients with brain metastases. J Clin Oncol. 2012;30:419-25.

14. Sperduto PW, Yang TJ, Beal K, Pan H, Brown PD, Bangdiwala A, Shanley R, Yeh N, Gaspar LE, Braunstein S, Sneed P, Boyle J, Kirkpatrick JP, Mak KS, Shih HA, Engelman A, Roberge D, Arvold ND, Alexander B, Awad MM, Contessa J, Chiang V, Hardie J, Ma D, Lou E, Sperduto W, Mehta MP. Estimating survival in patients with lung cancer and brain metastases: an update of the graded prognostic assessment for lung cancer using molecular markers (lungmolGPA). JAMA Oncol. 2017;3:827-31.

15. Nieder C, Hintz M, Bilger A, Oehlke O, Grosu AL. Validation of the graded prognostic assessment for melanoma using molecular markers (melanomamolGPA). J Clin Med Res. 2018;10:178-81.

16. Nieder C, Hintz M, Oehlke O, Bilger A, Grosu AL. Validation of the graded prognostic assessment for lung cancer with brain metastases using molecular markers (lung-molGPA). Radiat Oncol. 2017;12:107.

17. Nieder C, Hintz M, Grosu AL. Predicted survival in patients with brain metastases from colorectal cancer: is a current nomogram helpful? Clin Neurol Neurosurg. 2016;143:107-10.

18. Nieder C, Marienhagen K, Dalhaug A, Aandahl G, Haukland E, Pawinski A. Impact of systemic treatment on survival after whole brain radiotherapy in patients with brain metastases. Med Oncol. 2014;31:927.

19. Finkelmeier F, You SJ, Waidmann O, Wolff R, Zeuzem S, Bähr O, Trojan J. Bevacizumab in combination with chemotherapy for colorectal brain metastasis. J Gastrointest Cancer. 2016;47:82-8.

20. Qiu MZ, Shi SM, Chen ZH, Yu HE, Sheng H, Jin Y, Wang DS, Wang FH, Li YH, Xie D, Zhou ZW, Yang DJ, Xu RH. Frequency and clinicopathological features of metastasis to liver, lung, bone, and brain from gastric cancer: a SEER-based study. Cancer Med. 2018;7:3662-72.

21. Kumar A, Dagar M, Herman J, lacobuzio-Donahue C, Laheru D. CNS involvement in pancreatic adenocarcinoma: a report of eight cases from the Johns Hopkins Hospital and review of literature. J Gastrointest Cancer. 2015;46:5-8.

22. Nieder C, Pawinski A, Balteskard L. Colorectal cancer metastatic to the brain: time trends in presentation and outcome. Oncology. 2009;76:369-74.

23. Tanriverdi O, Kaytan-Saglam E, Ulger S, Bayoglu IV, Turker I, Ozturk-Topcu T. The clinical and pathological features of 133 colorectal cancer patients with brain metastasis: a multicenter retrospective analysis of the gastrointestinal tumors working Committee of the Turkish Oncology Group (TOG). Med Oncol. 2014;31:152.

24. Fowler A, Cook R, Biggs M, Little N, Assaad N, McDonald K. Survival of patients following neurosurgical treatment of colorectal adenocarcinoma 
metastasis in the northern Sydney-central coast area. J Clin Neurosci. 2008 15:998-1004.

25. Schoeggl A, Kitz K, Reddy M, Zauner C. Stereotactic radiosurgery for brain metastases from colorectal cancer. Int J Color Dis. 2002;17:150-5.

26. Skeie BS, Enger PØ, Ganz JC, Skeie GO, Parr E, Hatteland S. Gamma knife surgery of colorectal brain metastases: a high prescription dose of $25 \mathrm{~Gy}$ may improve growth control. World Neurosurg. 2013;79:525-36.

27. Amichetti M, Lay $G$, Dessi $M$, Orrù $S$, Farigu R, Orrù P, Farci D, Melis $S$,

Cagliari Neuro-Oncology Group. Results of whole brain radiation therapy in patients with brain metastases from colorectal carcinoma. Tumori. 2005;91: 163-7.

\section{Publisher's Note}

Springer Nature remains neutral with regard to jurisdictional claims in published maps and institutional affiliations.

Ready to submit your research? Choose BMC and benefit from:

- fast, convenient online submission

- thorough peer review by experienced researchers in your field

- rapid publication on acceptance

- support for research data, including large and complex data types

- gold Open Access which fosters wider collaboration and increased citations

- maximum visibility for your research: over $100 \mathrm{M}$ website views per year

At BMC, research is always in progress.

Learn more biomedcentral.com/submissions 